\title{
Fabrication of curcumin-loaded electrospun nanofiberous polyurethanes with anti-bacterial activity
}

\author{
A. Shababdoust ${ }^{1} \cdot$ M. Ehsani $^{1} \cdot$ P. Shokrollahi ${ }^{2} \cdot$ M. Zandi $^{2}$
}

Received: 25 June 2017 / Accepted: 16 November 2017 / Published online: 1 December 2017

(C) The Author(s) 2017. This article is an open access publication

\begin{abstract}
Two series of polyurethane (PU), based on polycaprolactone (PCL) as soft segments with two different molecular weights (2000 and $530 \mathrm{Da}$ ), and hexamethylene diisocyanate (HDI) and 1,4-butandiol (BDO) as hard segments were synthesized to fabricate curcumin-loaded electrospun nanofibrous PCL-based PU substrate. Chemical structures of the synthesized PUs were characterized by FTIR and NMR spectroscopy techniques. The thermal properties were analyzed by differential scanning calorimetry (DSC) and surface hydrophilicity was studied by static contact angle and bulk hydrophilicity was evaluated by water uptake test. Thereafter, bead-free PU nanofiberous substrate containing curcumin was fabricated by electrospinning and morphology of the mats was observed by scanning electron microscopy (SEM). Mechanical properties of the electrospun mats in comparison with polymeric films were assessed by a universal test machine. The in vitro release of curcumin was studied by UV-Vis spectroscopy. The optical density of the bacterial solutions was used to evaluate the antibacterial activity of the curcumin-loaded nanofibrous mats against Escherichia coli (E-coli ATCC: 25922). The results showed that curcumin-loaded PU synthesized by PCL with molecular weight of $2000 \mathrm{Da}$ displayed better mechanical properties as well as better antibacterial properties in wound dressing application.
\end{abstract}

\section{Graphical abstract}

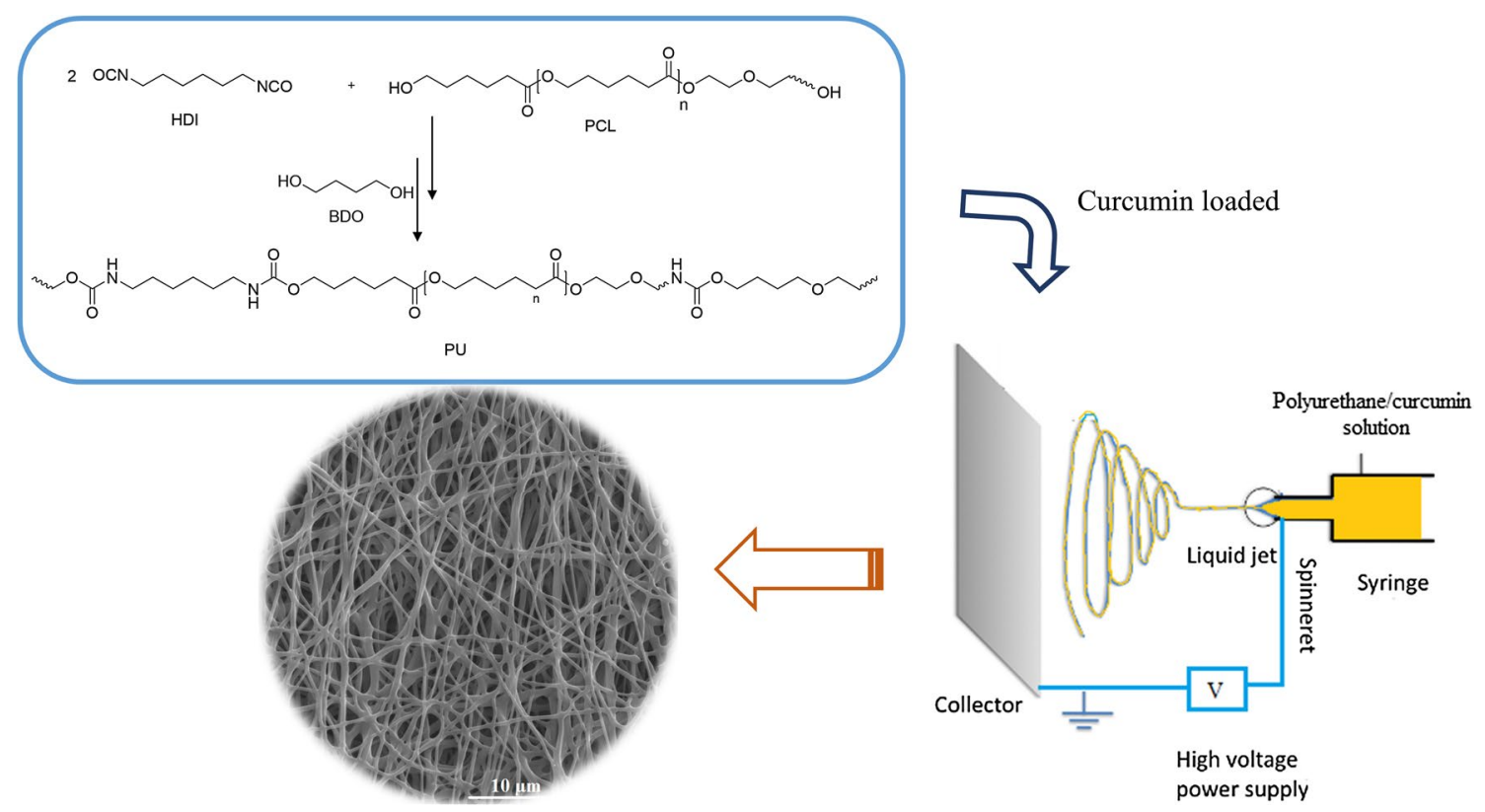

Keywords Polyurethane $\cdot$ Electrospinning $\cdot$ Curcumin release $\cdot$ Anti-bacterial activity

Extended author information available on the last page of the article 


\section{Introduction}

Polyurethane refers to a class of polymers containing urethane bond (-NHCOO-group) in the main chain (Gogolewski 1989) that are made by reaction of diisocyanate, a polyol and a small diol and or diamine molecule used as chain extenders (Krol 2007). Due to various structures of the original reactants and the existence of soft and hard segments and the resulting interactions between them, polyurethanes show a wide range of physical and mechanical properties, which make them unique as polymeric materials in many applications such as resins (Pathak et al. 2009), adhesives (Malucelli et al. 2005), foams (Jain and Pradeep 2005), waterborne paints (Yang et al. 2004) and rubbers (Varghese et al. 2004). PUs are used in biomedical applications such as artificial heart valve (Yu et al. 1989), blood vessel (Pennings et al. 1990), joints (Scholes et al. 2007) as well as controlled release system (Sivak et al. 2008) and wound dressing (Unnithan et al. 2014).

Curcumin, known as (bis-1,7-[4-hydroxy-3methoxyphenyl]-hepta-1,6-dione), is derived from curcuma longa (Goel et al. 2008; Himesh et al. 2011) and the yellow pigment known as turmeric (Gunes et al. 2013). Curcumin has many medical applications because of outstanding properties such as anti-inflammatory (Chandra and Gupta 1972; Huei-Chen et al. 1992), antioxidant (Erenoğlu et al. 2011), burn wound healing (Kulac et al. 2013), antifungal (Martins et al. 2009) and antibacterial (Gunes et al. 2013) agent.

Electrospinning is a method of fiber fabrication with diameters ranging from micro-meter to nano-scale by accelerating a jet of charged polymer solution in an electric field (Natu et al. 2011). These fibers can be produced from natural (Zhang et al. 2005) and synthesized polymers (Demir et al. 2002; Saeed et al. 2017) with different applications such as filteration (Gopal et al. 2006), catalyst (Patel et al. 2007) drug delivery (Zeng et al. 2003), tissue engineering ( $\mathrm{Li}$ et al. 2002) and wound dressing (Khil et al. 2003). In some studies polyurethane has been used as carrier for curcumin (Abdollahi et al. 2015; Nagarajan et al. 2011; Souguir et al. 2013) and also in some studies curcumin is loaded into a synthesized polymer such as cellulose acetate (Suwantong et al. 2007), polyvinylalcohol (PVA) (Sun et al. 2013), zein (Brahatheeswaran et al. 2012), poly (lactic acid) (PLA) (Chen et al. 2010), poly (dl-lactic-co-glycolic) acid (PLGA) (Sampath et al. 2014), poly( $\varepsilon$-caprolactone) (PCL) (Merrell et al. 2009) and p(HEMA) (Merrell et al. 2009). Based on our knowledge, we may declare that electrospun nanofibres of polyurethane containing curcumin are not fabricated before.

In this study we have synthesized polyurethane, a biocompatible polymer as carrier for antibacterial drug by hexamethylene diisocyanate (HDI) as diisocyanate, polycaprolactone (PCL) as biocompatible polyol and butanediol
(BDO) as chain extender. To control the mechanical properties as well as the drug loading content of the synthesized polymeric system, two different molecular weights of PCL (530 and $2000 \mathrm{Da}$ ) were introduced into the polymer backbone; with curcumin, an anti-bacterial and wound healing agent, as loading drug to fabricate curcumin-loaded polyurethane nanofibrous mat. Nanofibrous containing curcumin was fabricated by electrospinning process because of many advantages such as large surface area and superior physical properties. Following the fabrication of drug-loaded electrospun nanofibers, the anti-bacterial properties of the fabricated mats were investigated by comparing two systems based on PCL molecular weights.

\section{Experimental}

\section{Materials}

Polycaprolactone (PCL) $\left(M_{\mathrm{n}} 2000\right.$ and $\left.530 \mathrm{Da}\right)$ was purchased from Sigma-Aldrich; 1,6-hexamethylene diisocyanate (HDI), 1,4-butanediol (BDO), 1,2-dicholoethane, stannous octoate, curcumin (Cur) and 1,1,1,6,6,6-hexafluoroisopropanol (HFIP) were purchased from Merck Co. PCL and $\mathrm{BDO}$ were dried prior to use under vacuum at $80{ }^{\circ} \mathrm{C}$ for $24 \mathrm{~h}$.

\section{Synthesis of polyurethanes}

Polyurethanes were synthesized by a two-step polymerization method. Briefly, in the first step $1 \mathrm{mmol}$ PCL $\left(M_{\mathrm{n}} 2000\right.$ and $530 \mathrm{Da}$, in separate procedures, referred to as PCL2000 and PCL530 hereafter) was transferred to a three-necked flask, and were added 2 mmol HDI with 1,2-dichloroethane and $0.1 \% \mathrm{wt}$ stannous octoate. The mixture was heated for $4 \mathrm{~h}$ at $70{ }^{\circ} \mathrm{C}$ under dry nitrogen atmosphere. After $4 \mathrm{~h}$, $1 \mathrm{mmol}$ BDO was added into the reaction system and allowed to continue for $24 \mathrm{~h}$ under dry nitrogen atmosphere. The product was cooled down and then precipitated in $n$-hexane. The precipitate was dissolved in chloroform and re-precipitated in $n$-hexane to eliminate stannous octoate and possible oligomeric residues. Final product was dried under vacuum at $40{ }^{\circ} \mathrm{C}$ for $72 \mathrm{~h}$. Table 1 shows molar ratio and hard segment content of the synthesized polyurethane.

Table 1 Sample coding, molar ratio and hard segment content of the synthesized polyurethane

\begin{tabular}{lllll}
\hline $\begin{array}{l}\text { Sample } \\
\text { code }\end{array}$ & $\begin{array}{l}\text { HDI } \\
(\mathrm{mmol})\end{array}$ & $\begin{array}{l}\text { PCL (Mw) } \\
(\mathrm{mmol})\end{array}$ & $\begin{array}{l}\text { BDO } \\
(\mathrm{mmol})\end{array}$ & $\begin{array}{l}\text { Hard seg- } \\
\text { ment content } \\
(\%)\end{array}$ \\
\hline PU2000 & 2 & $1(2000 \mathrm{Da})$ & 1 & 17.5 \\
PU530 & 2 & $1(530 \mathrm{Da})$ & 1 & 44.6 \\
\hline
\end{tabular}




\section{Characterization}

FTIR and ${ }^{1} \mathrm{H}$ NMR spectroscopy were used to identify the chemical structures of the synthesized copolymers, trace the reaction and determine the polyols ratio in the final products. Infrared spectroscopy was performed on a Bruker instrument (Aquinox 55, Germany) in the range of $400-4000 \mathrm{~cm}^{-1}$. The ${ }^{1} \mathrm{H}$ NMR spectrum was recorded in $\mathrm{CDCl}_{3}$ as a solvent using a 500-MHz Bruker spectrometer (DRX-500 Avance, Germany).

Thermal behavior of the samples was evaluated by a Mettler differential scanning calorimeter (DSC) (Star SW 10.00, Switzerland). The copolymers were heated to $180^{\circ} \mathrm{C}$ and cooled down to $-80^{\circ} \mathrm{C}$ and re-heated to $180{ }^{\circ} \mathrm{C}$. Thermal transitions were extracted from the second heating run.

Mechanical properties of the copolymers were investigated by a Santam mechanical testing machine (STM20 , with a $200 \mathrm{~N}$ load cell, Iran), at a crosshead speed of $5 \mathrm{~mm} \mathrm{~min}^{-1}$, according to ASTM D 638. The tensile strength $\left(\sigma_{\mathrm{s}}\right)$, Young's moduli $(E)$ and elongation-at-break $(\varepsilon)$ of polymer films $(30 \mathrm{~mm} \times 10 \mathrm{~mm} \times 0.3 \mathrm{~mm})$ were measured. The reported data were the average data of three specimens.

Surface hydrophilicity was investigated by water contact angle method. The reported results were the average of three measurements using a Kruss G10 contact angle measuring system (Germany).

Bulk hydrophilicity was studied by water uptake of copolymers according to the reference (Skarja and Woodhouse 1998) and was defined as the difference of the wet mass $\left(w_{2}\right)$ and dry mass $\left(w_{1}\right)$ of the films:

Water uptake $(\%)=\frac{\left(w_{2}-w_{1}\right)}{w_{1}} \times 100$.

\section{Fabrication and characterization of curcumin-loaded electrospun nanofibers}

For fabrication the bead-free electrospun mat of polyurethane and polyurethanes/curcumin, two separate solutions were prepared by (1) $20 \mathrm{wt} \%$ polyurethane, synthesized by PCL of $M_{\mathrm{n}} 2000 \mathrm{Da}$ and (2) $30 \mathrm{wt} \%$ polyurethane synthesized by PCL of $M_{\mathrm{n}} 530 \mathrm{Da}$ in HFIP. To achieve the polymeric solutions containing curcumin, 5\% curcumin with respect to the PU content was added to the PU2000 and PU530 solutions and $10 \%$ curcumin with respect to the PU2000.

Electrospinning was performed using the following parameters: $20 \mathrm{kV}$ applied voltage, $21 \mathrm{~cm}$ tip-to-collector distance, $0.5 \mathrm{~mL} \mathrm{~h}^{-1}$ solution flow rate and $1000 \mathrm{rpm}$ collector rotation. The electrospun mats were dried under vacuum to eliminate the residual solvent for $72 \mathrm{~h}$.

Morphology of the electrospun nanofibers were studied by scanning electron microscopy (SEM: VEGA 3SBHI
TESCAN Brno). The average fiber diameter was calculated by analysis of around 150 fibers in SEM images using the Image $\mathbf{J}$ software and the histogram of frequency/fiber diameter for each sample was obtained.

Mechanical properties of the electrospun nanofiber mats were investigated by a Santam mechanical testing machine (model STM-20, with a $10 \mathrm{~N}$ load cell, Iran) at a crosshead speed of $1 \mathrm{~mm} \mathrm{~min}^{-1}$. The tensile strength $\left(\sigma_{\mathrm{s}}\right)$, Young's moduli $(E)$ and elongation-at-break $(\varepsilon)$ of the $5 \%$ curcumin loaded electrospun polymer mats $(30 \mathrm{~mm} \times 10 \mathrm{~mm} \times 0.3 \mathrm{~mm})$ were measured. The reported data were the average data of three specimens.

\section{Curcumin release study}

Because of low solubility of curcumin in water, its release was studied in a mixture of water and ethanol (70:30) as a release medium (Alexis et al. 2004; Zhu et al. 2015). So, 20-30 mg of $5 \%$ curcumin-loaded and $10-20 \mathrm{mg}$ of $10 \%$ curcumin-loaded electrospun mats were placed into $15 \mathrm{~mL}$ release medium and transferred into the shaking incubator at $37^{\circ} \mathrm{C}$ and $100 \mathrm{rpm}$.

At a regular time interval, the liquid media were replaced by aliquots of fresh media. Next, the sample solutions were analyzed at wavelength of $429 \mathrm{~nm}$ by a UV spectrophotometer. Accumulative drug release percent was calculated by using a calibration curve and it was plotted versus time. All measurements were performed three times and the results were average values of at least three sequencing tests.

\section{Invitro anti-bacterial properties}

The optical density values of the bacterial solutions were used to evaluate the antibacterial activity of the curcumin-loaded nanofibrous mats against Escherichia coli (E-coli ATCC: 25922). The bacterial suspensions were prepared by 0.5 McFarland bacterial suspension method briefly outlined as follows: $10^{8}$ colony-forming units per milliliter $\left(\mathrm{CFU} \mathrm{mL} \mathrm{mL}^{-1}\right)$ was diluted to $10^{5}\left(\mathrm{CFU} \mathrm{mL} \mathrm{m}^{-1}\right)$ in DifcoTM nutrient broth solution. Curcumin-loaded electrospun mats, each $50 \mathrm{mg}$, were cut and after sterlization by UV-lamp and were placed in $5 \mathrm{~mL}$ of bacterial solution. The mixtures were cultured at $37{ }^{\circ} \mathrm{C}$ in a shaking incubator for $48 \mathrm{~h}$. The turbidity of the medium, which represented the bacterial growth, was measured after $48 \mathrm{~h}$ using a spectrophotometer at $600 \mathrm{~nm}$ wavelength. The antibacterial efficiency of the curcumin-loaded nanofiber mats was then calculated from the following equation (Nguyen et al. 2011):

Antibacterial efficiency $(\%)=\left(1-\frac{\mathrm{OD}_{1}}{\mathrm{OD}_{2}}\right) \times 100$, 
where $\mathrm{OD}_{1}$ and $\mathrm{OD}_{2}$ are the optical densities of the bacteria in the medium and the bacteria in solutions containing different nanofiber mats, respectively, for $48 \mathrm{~h}$.

\section{Results and discussion}

\section{Polyurethane synthesis}

A two-step synthesis of polyurethanes (prepolymers and polyurethane) is shown in Fig. 1. At first, PCL was reacted with HDI and an isocyanate-terminated prepolymer was prepared. After that 1,4-butandiol (BDO) was reacted with the prepolymer and the final product was formed. FTIR spectroscopy data indicate that the reaction has been completed.

FTIR spectra of the polymers show -NH of urethane bond absorbance at $3300-3400$ and $1535 \mathrm{~cm}^{-1}$. The peaks, observed at 2944 and $2873 \mathrm{~cm}^{-1}$, are associated with the asymmetric and symmetric $-\mathrm{CH}_{2}$ groups. The peak at $1730 \mathrm{~cm}^{-1}$ is assigned to the stretching vibration of $\mathrm{C}=\mathrm{O}$ groups. The peaks located at 3316, 1730, 1457 and $1100 \mathrm{~cm}^{-1}$ correspond to the $-\mathrm{NH},-\mathrm{C}=\mathrm{O},-\mathrm{CNH}$ and $-\mathrm{C}=\mathrm{O}$

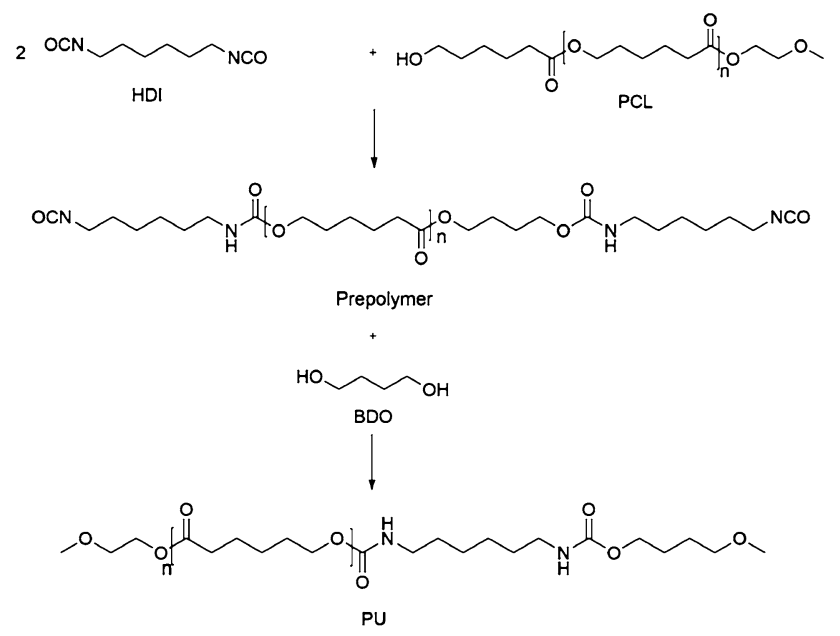

Fig. 1 Schematic presentation of a two-step synthesis of polyurethane absorptions and confirm the presence of -NHCOO groups in the synthesized polyurethane (Pradhan and Nayak 2012). FTIR spectrum is shown in Fig. 2 and there is no difference between the FTIR spectrum of PU2000 and PU530.

${ }^{1} \mathrm{H}$ NMR spectrum and chemical structure of PCL2000 and PU2000 are shown in Fig. 3 and protons are marked on ${ }^{1} \mathrm{H}$ NMR spectral peaks. The appearance of $\mathrm{H}_{\mathrm{f}}$ in $4.8 \mathrm{ppm}$ on the spectrum of PU2000 compared with that of PCL2000 indicates formation of urethane group in the product $(\mathrm{Li}$ et al. 2014).

Thermal transition temperatures of two series of polyurethane are summarized in Table 2. Figure 4 shows thermograms of PU530 and PU2000. As it can be seen in Fig. 4 PU530 has shown no melting temperature for the soft segments. It seems that the hard segment formation has probably interrupted crystallization of the soft segments (Skarja and Woodhouse 1998) and soft segments remain amorphous. Glass transition temperature of PU2000 $\left(-55.98{ }^{\circ} \mathrm{C}\right)$ is lower than PU530 $\left(-44.78^{\circ} \mathrm{C}\right)$ because of higher soft segment content and longer chain which could have led to facilitate chain mobility (Bajsic et al. 2000; Loh et al. 2008). The soft segment content of PU2000 is $82.5 \%$ and that of PU530 is $55.4 \%$ and hard segments melting points are observed at $130.61{ }^{\circ} \mathrm{C}$ for PU530 and $119.16^{\circ} \mathrm{C}$ for PU2000. The lower enthalpy in melting point of PU2000 $\left(-2.97 \mathrm{~J} \mathrm{~g}^{-1}\right)$ compared to PU530 $\left(-44.68 \mathrm{~J} \mathrm{~g}^{-1}\right)$ is an indication of greater crystallinity of PU530 hard segments relative to those of PU2000.

Figure 5 shows stress-strain curves of the polyurethanes and modulus, tensile strength and strain-at-break extracted and reported in Table 3. Polyurethanes have hard segments, made of diisocyanate and chain extender which are responsible for the hardness of the polymer, and soft segments consisting of polyol which is responsible for the flexibility of the polymer. Also, they have microdomains formed by interactions between hard segments as hard domains and soft segments as soft domains. As it is clear hard domains act like filler through soft domains, so, polyurethane can be considered as a nanocomposite (Clough et al. 1968). Increasing hard segment leads to higher modulus and
Fig. 2 FTIR spectrum of $\mathbf{a}$ PU2000 and b PU530
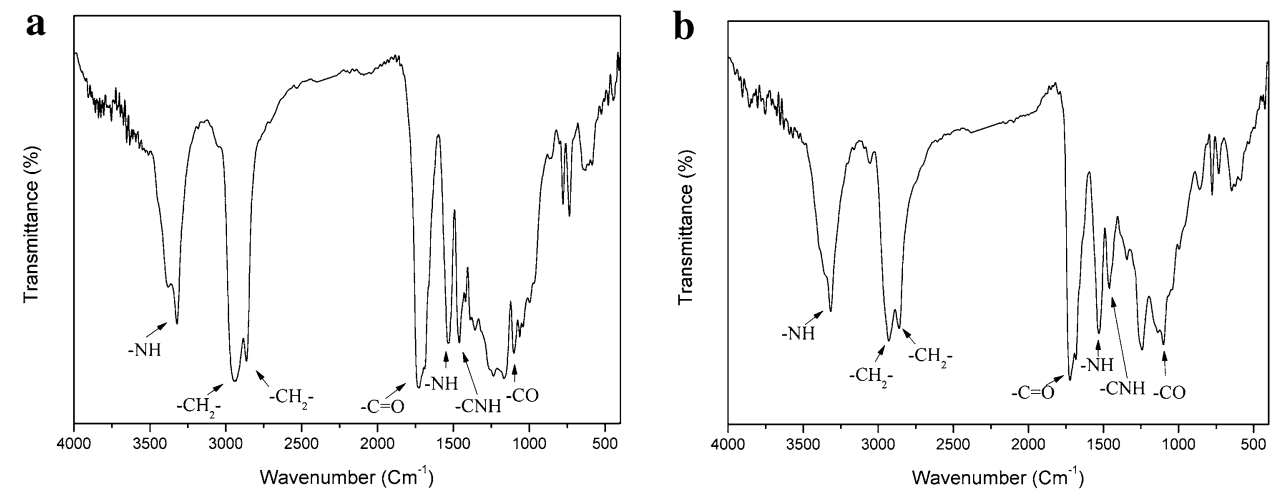


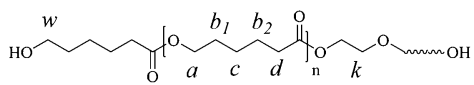

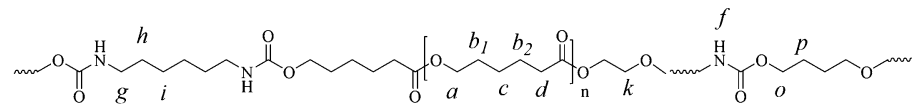
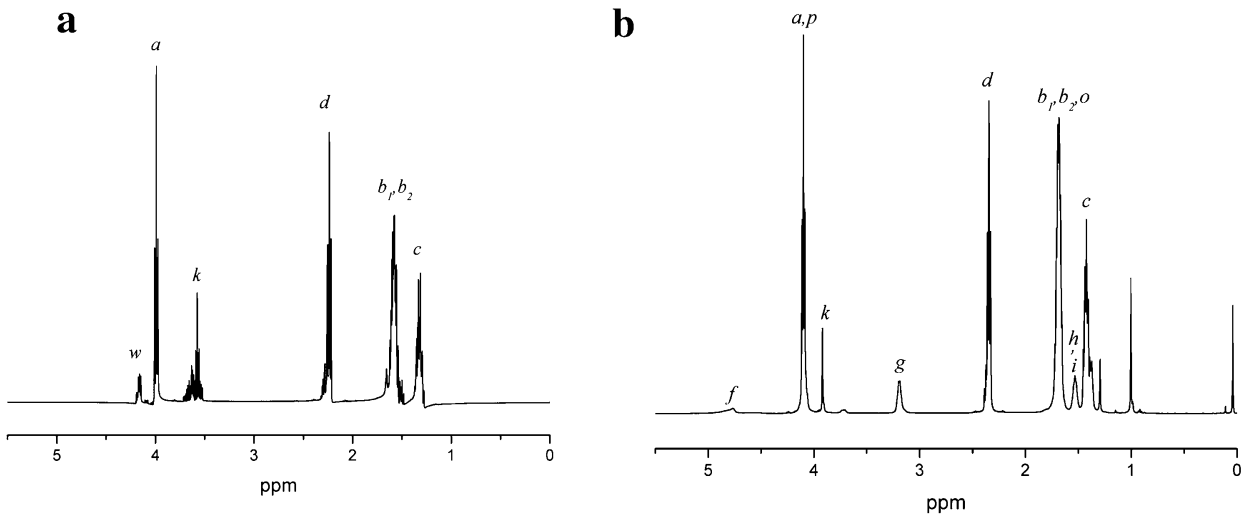

Fig. $3{ }^{1} \mathrm{H}$ NMR spectrum of a PCL2000 and b PU2000

Table 2 Thermal transitions of polyurethanes

\begin{tabular}{lcccc}
\hline Sample code & $T_{\mathrm{gs}}\left({ }^{\circ} \mathrm{C}\right)$ & $T_{\mathrm{ms}}\left({ }^{\circ} \mathrm{C}\right)$ & $T_{\mathrm{mh}}\left({ }^{\circ} \mathrm{C}\right)$ & $\Delta H_{\mathrm{m}}\left(\mathrm{J} \mathrm{g}^{-1}\right)$ \\
\hline PU2000 & -55.98 & 32.50 & 119.16 & -2.97 \\
PU530 & -44.78 & - & 130.61 & -44.68 \\
\hline
\end{tabular}

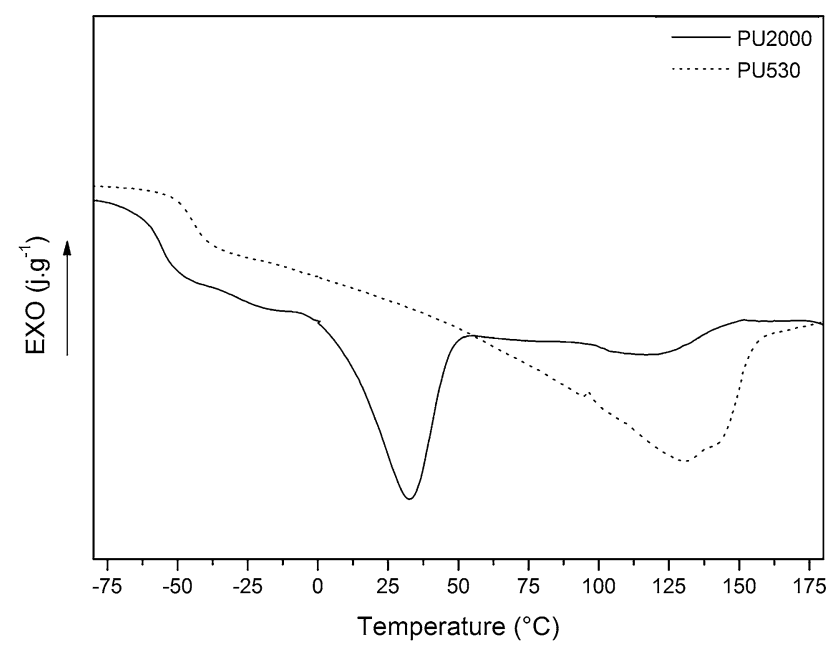

Fig. 4 DSC curves (second heating cycle) of PU530 and PU2000

lower strain-at-break. On the other hand, increasing soft segment leads to greater flexibility followed by higher strain-at-break and lower modulus (Allport and Mohajer 1973; Bonart 1968; Clough and Schneider 1968). It can be seen that PU530 has greater modulus (4.87 MPa) and lower strain-at-break (207\%) compared to PU2000 (0.75 MPa modulus and $1300 \%$ strain-at- break) because

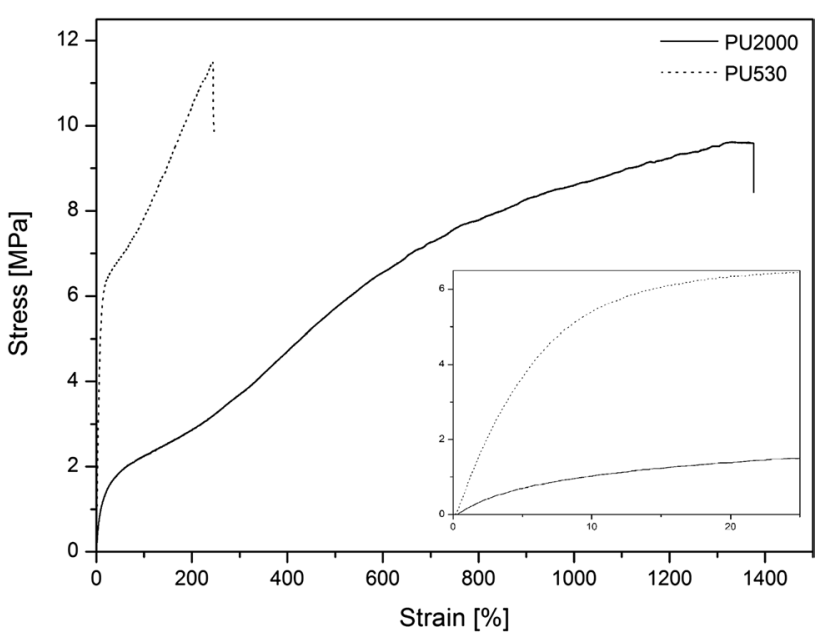

Fig. 5 Stress-strain curves of PU2000 and PU530

Table 3 Mechanical properties of polyurethanes

\begin{tabular}{lccc}
\hline Sample code & Modulus (MPa) & $\begin{array}{l}\text { Tensile strength } \\
(\mathrm{MPa})\end{array}$ & $\begin{array}{l}\text { Strain at break } \\
(\%)\end{array}$ \\
\hline PU2000 & $0.75 \pm 0.07$ & $9.80 \pm 0.20$ & $1300 \pm 30$ \\
PU530 & $4.87 \pm 0.18$ & $11.74 \pm 0.36$ & $207 \pm 31$ \\
\hline
\end{tabular}

of the former higher hard segment content (44.6\%). The urethane group density has been increased and, therefore, it has increased the probability of intermolecular interaction which has led to greater resistance against deformation. Meanwhile, PU2000 has greater flexibility because of its higher soft segment content (82.5\%). 
Fig. 6 Water contact angle of PU2000 and PU530

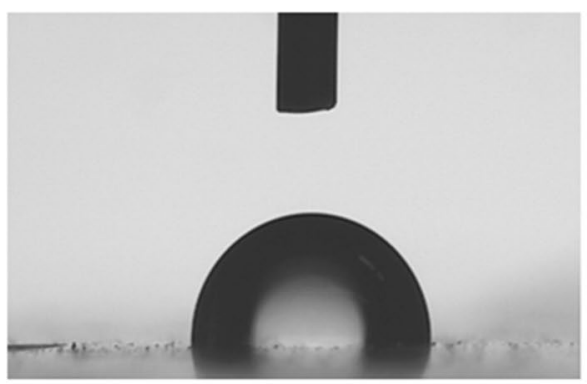

PU530

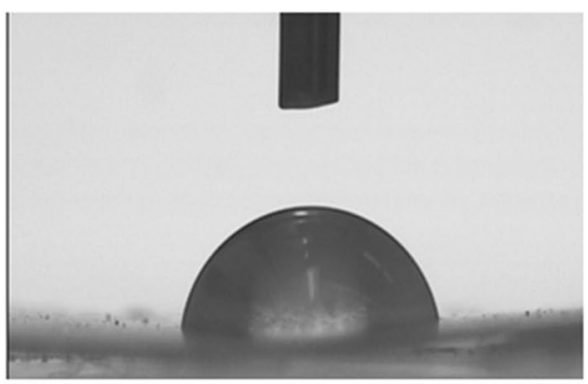

PU2000
Table 4 Water contact angle and water uptake data of PU530 and PU2000

\begin{tabular}{lll}
\hline Sample code & Contact angle $\left(^{\circ}\right)$ & Water uptake $\left(^{\circ}\right)$ \\
\hline PU2000 & $85.8 \pm 2.6$ & $3.4 \pm 0.8$ \\
PU530 & $97.0 \pm 1.2$ & $2.1 \pm 0.5$ \\
\hline
\end{tabular}

Surface hydrophilicity of the polyurethanes was analyzed by static water contact angle measurements for which the results are shown in Fig. 6. Contact angle and water uptake data are reported in Table 4. As can be seen the increase in molecular weight of polycaprolactone has increased hydrophilicity as shown by lower water contact angle $\left(85.8^{\circ}\right.$ for PU2000 and $97^{\circ}$ for PU530) and small increase in water uptake (3.4\% for PU2000 and 2.1\% for PU530).
Water uptake of PU2000 and PU530 shows no significant difference as reported by Skrja et al. (Skarja and Woodhouse 1998). A little higher water uptake of PU2000 may be because of more hydrophobicity of PCL530 and more hydrophilic surface of PU2000.

\section{Curcumin-loaded electrospun nanofibers}

To fabricate PU nanofibrous substrate loaded curcumin, electrospinning method has been used because of its many advantages such as large surface area. Morphology of the nanofibers was investigated by SEM and is illustrated in Figs. 7 and 8 . As can be seen in these figures, surface of the nanofiber is smooth and no bead is observed. There is no crystal of curcumin observed which means curcumin has been completely incorporated into the fibers ( Fu et al.
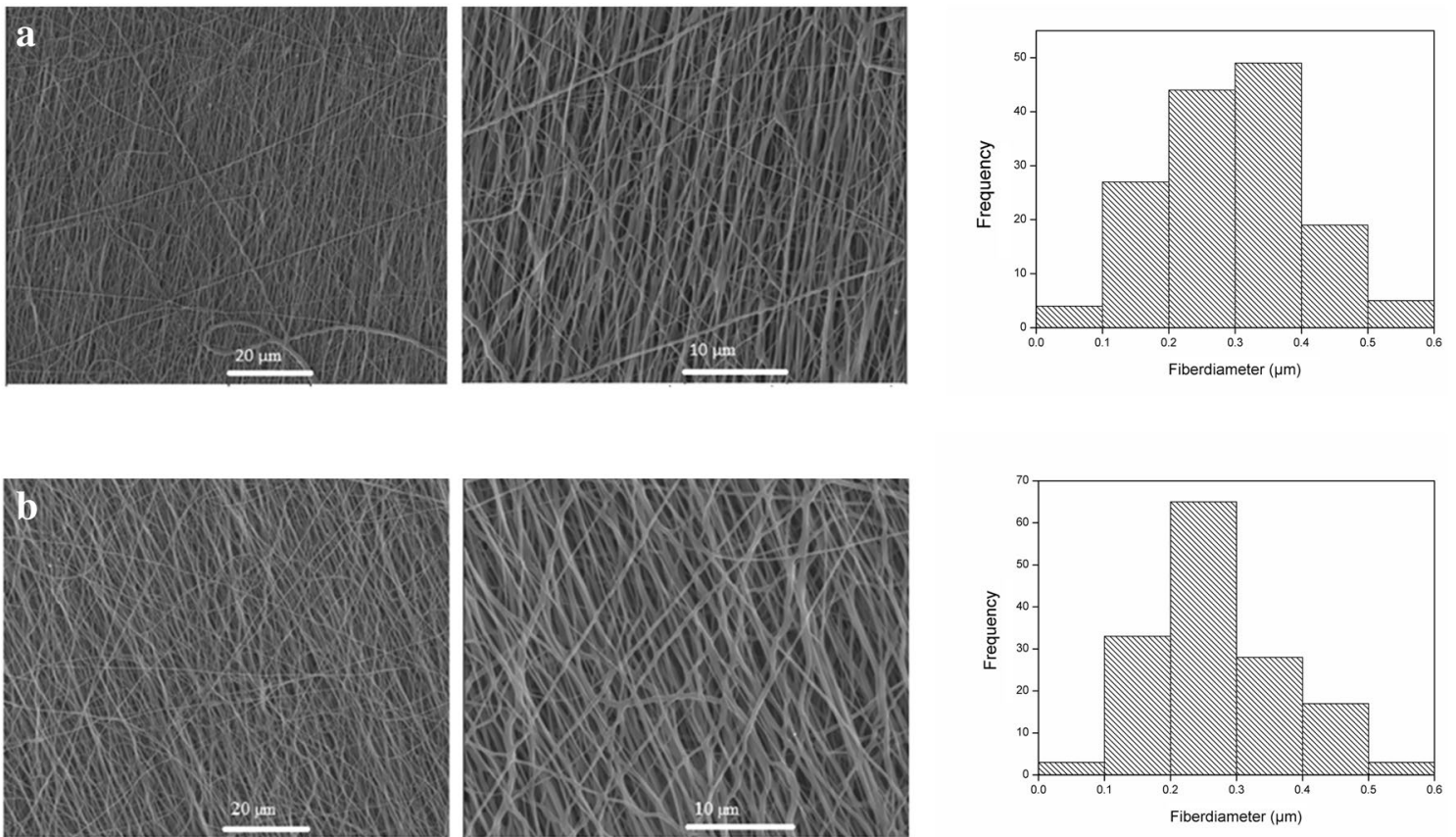

Fig. 7 SEM images of PU530: a 0\% curcumin loaded b 5\% curcumin loaded with related histogram 

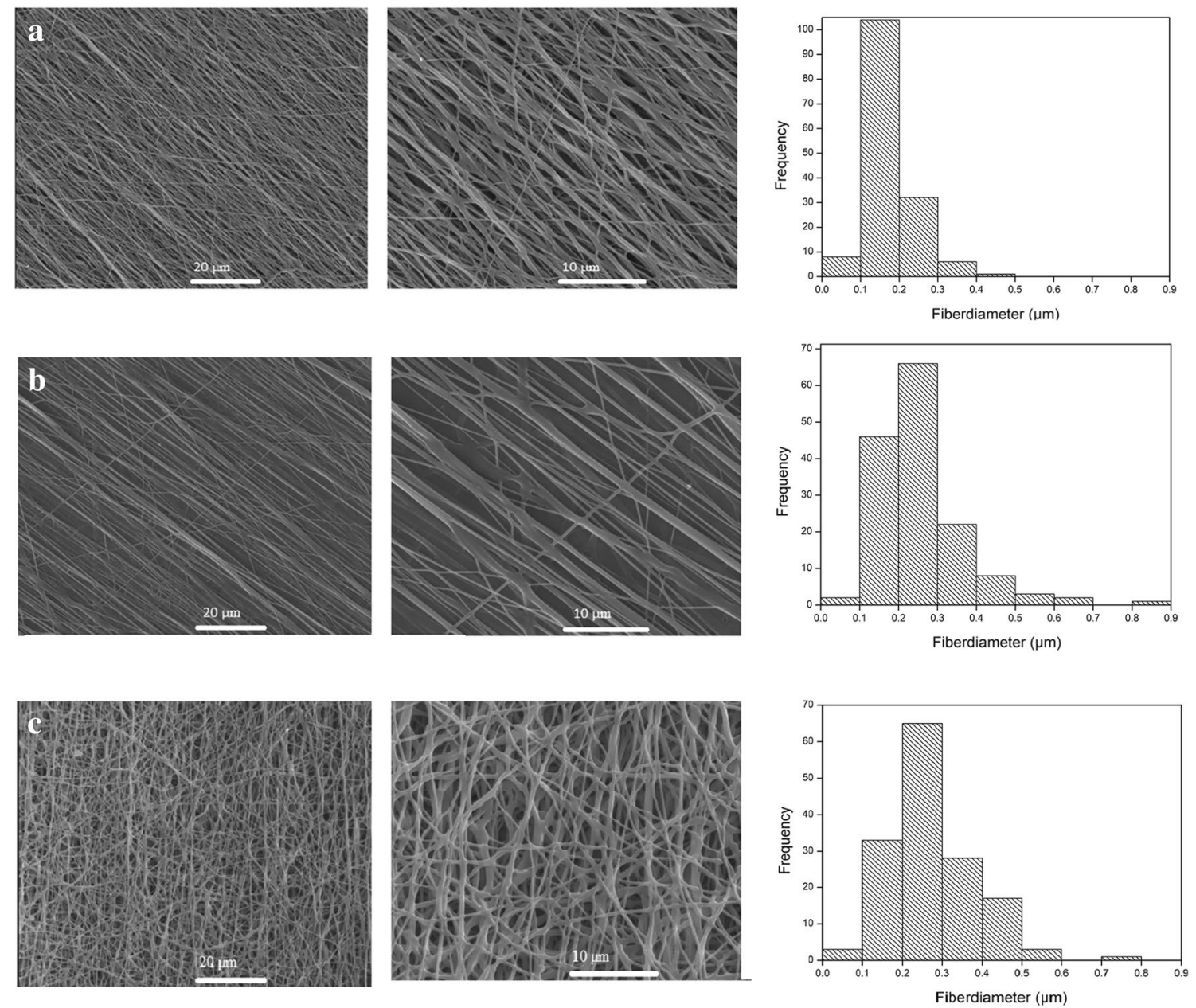

Fig. 8 SEM images of PU2000: a 0\% curcumin loaded b 5\% curcumin loaded c 10\% curcumin loaded with related histogram

Table 5 Average fiber diameter of electrospun nanofiber polyuerthanes

\begin{tabular}{lll}
\hline Sample code & Curcumin content (\%) & $\begin{array}{l}\text { Average fiber } \\
\text { diameter (nm) }\end{array}$ \\
\hline PU2000 & 0 & $172 \pm 64$ \\
& 5 & $256 \pm 110$ \\
PU530 & 10 & $274 \pm 107$ \\
& 0 & $200 \pm 80$ \\
& 5 & $284 \pm 112$ \\
\hline
\end{tabular}

2014). The average fiber's diameter is shown in Table 5. Average diameter is increasing by incorporation of curcumin in nanofiber. Nanofiber diameters of PU530 and PU2000 are summarized in Table 5. Incorporation and increases of curcumin in nanofibers have led to higher average fiber diameter, as reported by some researchers on curcumin incorporated into other polymers (Chen et al. 2010; Suwantong et al. 2007). Increases in average fiber
Table 6 Mechanical properties of electrospun nanofibers mats of polyurethanes

\begin{tabular}{lrll}
\hline Sample code & Modulus (MPa) & $\begin{array}{l}\text { Tensile strength } \\
(\mathrm{MPa})\end{array}$ & $\begin{array}{l}\text { Strain at break } \\
(\%)\end{array}$ \\
\hline PU2000 & $5.96 \pm 0.13$ & $6.90 \pm 0.30$ & $65 \pm 8$ \\
PU530 & $18.50 \pm 2.12$ & $2.65 \pm 0.21$ & $18 \pm 1$ \\
\hline
\end{tabular}

diameter can be disregarded by the processing condition (e.g., polymer concentration, voltage, tip-to-collector distance and flow rate) which all lead to constant fiber diameter. It seems that the incorporation of drug into polymer nanofibers may be the only parameter which is responsible in fibers of greater diameter. Stress-strain curves are shown in Fig. 9 and the mechanical properties are reported in Table 6. Mechanical properties of the 5\% curcumin loaded electrospun mats follow the same trend as mechanical behaviors of the copolymer films. As it was mentioned above, PU530 has higher modulus because of higher hard 


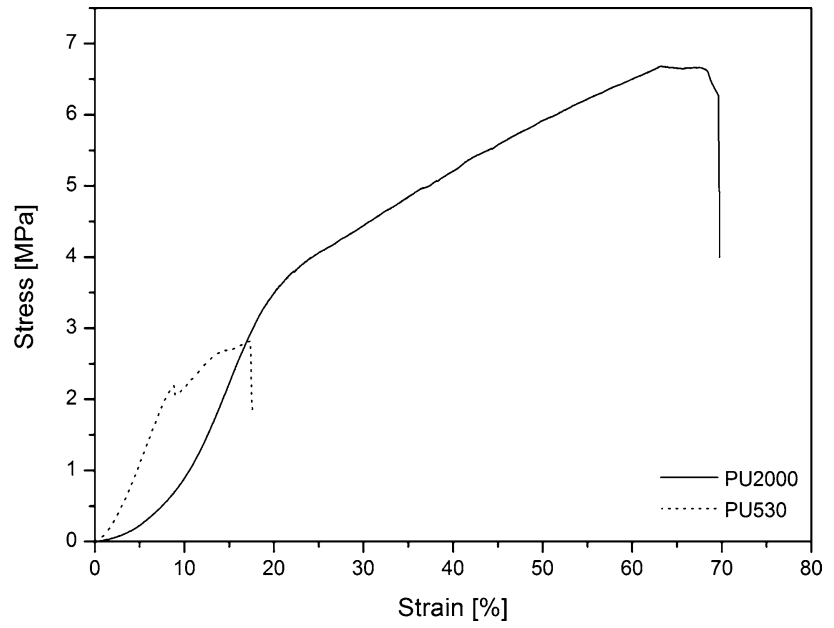

Fig. 9 Stress-strain curves of the electrospun nanofibers of PU2000 and PU530

segment content and PU2000 has more flexibility because of higher soft segment content. In this study we have used $5 \%$ curcumin loaded electrospun mats which have led to higher elongation and higher strength-at-break and lower modulus compared with electrospun mates without curcumin (Ranjbar-Mohammadi and Bahrami 2016).

To acquire bead free electrospun fibers which is the aim of this study, curcumin loading capacity has been restricted. The highest curcumin loading for PU530 is found $5 \%$ because it cannot be dissolved at higher amount, and, therefore, $10 \%$ curcumin has just been loaded in PU2000 because of lower polymer solution concentration.

\section{Curcumin release study}

Curcumin release curve is plotted by the accumulative curcumin release (mg released curcumin divided by initial curcumin loaded) versus time and is shown in Fig. 10. Curcumin release in both polyurethanes follows the same pattern in which at first they show a burst release (for $24 \mathrm{~h}$ ) because of dissolution of curcumin accumulated onto the surface followed by the sustained release of the interior curcumin over 11 days. As it is obvious in PU2000 with more hydrophilic surface, the burst release is lower than PU530, because curcumin prefers to remain in hydrophobic segments of the polymer (Sampath et al. 2014). PU2000 with $10 \%$ curcumin loading showed more burst release than PU2000 (loaded by $5 \%$ ). It is because PU2000 surface has contained more curcumin and the maximum amount of release of PU2000 with $10 \%(\sim 80 \%)$ is still higher than the polyurethanes loaded by $5 \%(\sim 72 \%)$, as it is indicated in Fig. 10.

\section{In vitro anti-bacterial properties}

The results of anti-bacterial properties of curcumin-loaded polyurethane mats against $10^{5} \mathrm{CFU} \mathrm{ml}^{-1}$ of E.coli are shown in Fig. 11. The electospun mats, of each $50 \mathrm{mg}$, were placed
Fig. 10 Curcumin release study in release medium (70:30 water:ethanol)

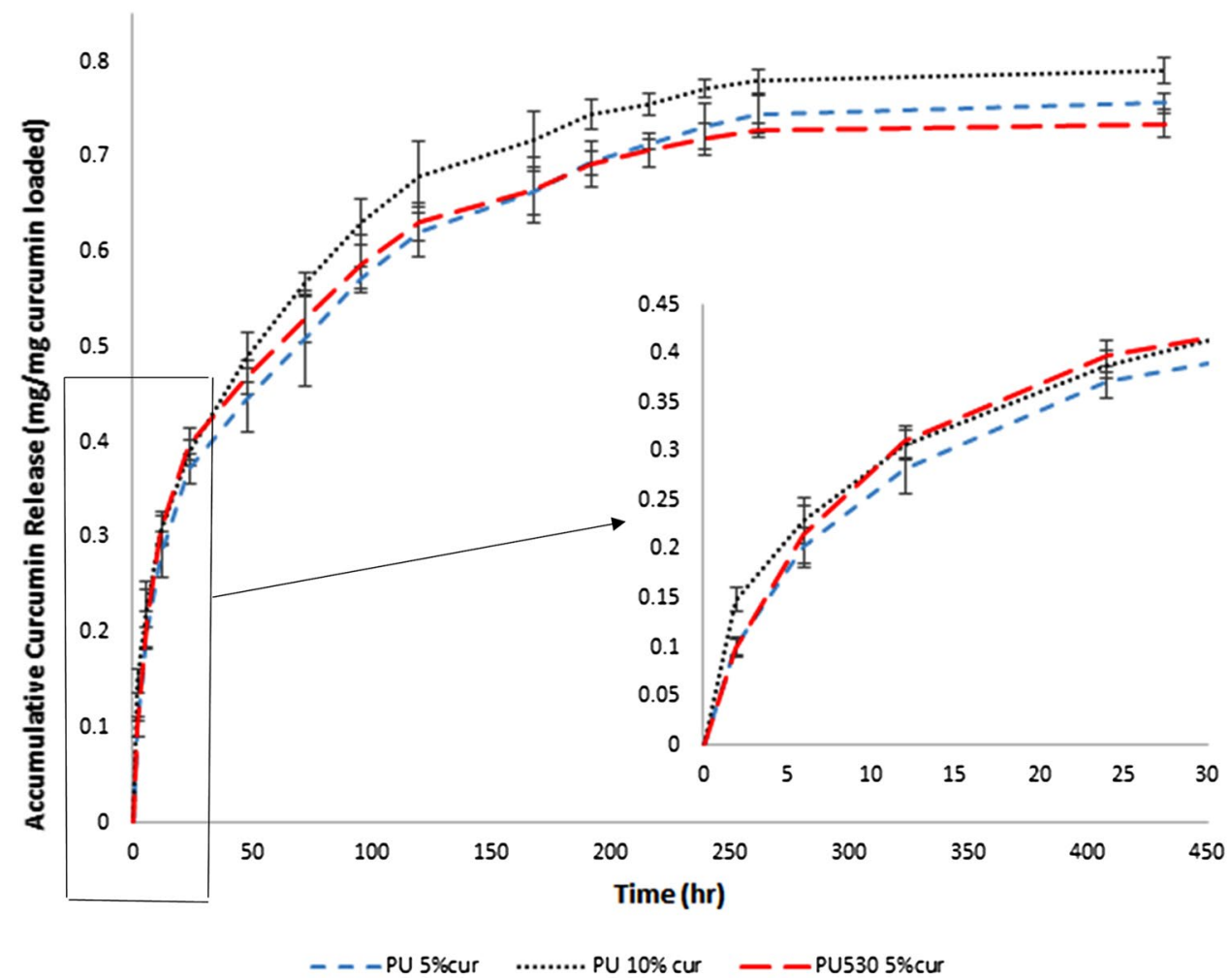




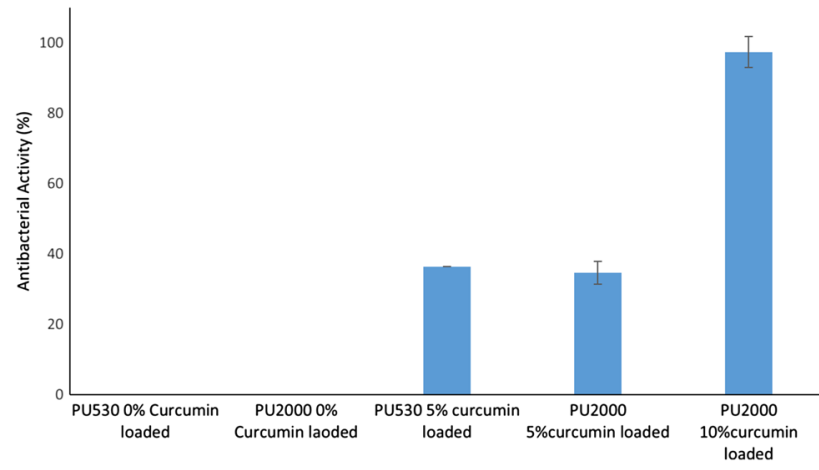

Fig. 11 Antibacterial activity of the electrospun curcumin-loaded polyurethanes

into $5 \mathrm{~mL}$ bacterial solution. Each mat was loaded by $5 \%$ curcumin and contained $\sim 2.5 \mathrm{mg}$ curcumin and the PU 2000 electrospun mat which was loaded by $10 \%$ curcumin contained approximately $5 \mathrm{mg}$ curcumin. In this research, a turbidimetric assay was used to study the anti-bacterial activity of the curcumin-loaded electrospun polyurethane nanofibers (Aulton 2002). Therefore, the maximum concentration of curcumin in solution for 5\% curcumin-loaded PU530 and PU2000 and 10\% curcumin-loaded PU2000 would be $\sim 500$, 500 and $1000 \mu \mathrm{g} \mathrm{mL}^{-1}$, respectively. The minimum inhibitory concentration (MIC) of curcumin against Escherichia coli ATCC:25922 is $163 \mu \mathrm{g} \mathrm{mL} \mathrm{m}^{-1}$ (Gunes et al. 2013). As regards the release process by $\sim 42 \%$ in $48 \mathrm{~h}$ there were 48 and $45 \%$ released from 5 to $10 \%$ curcumin-loaded PU2000 and 5\% curcumin-loaded PU530 were obtained which implied approximately 210 and $480 \mu \mathrm{g} \mathrm{mL}^{-1}$ curcumin release from 5 to $10 \%$ curcumin-loaded mats, respectively. It could be concluded that the anti-bacterial efficiency of $10 \%$ loaded PU2000 showed higher anti-bacterial efficiency by elimination of most bacteria (97\% anti-bacterial activity).

\section{Conclusion}

In this study two series of polyurethanes were synthesized in a two-step polymerization based on PCL $\left(M_{\mathrm{n}} 530\right.$ and 2000 Da), HDI and BDO. FTIR and ${ }^{1} \mathrm{H}$ NMRspectroscopy characterization confirmed completion of polyurethanes synthesis. Thermal properties of the polyurethanes were studied by DSC and the results showed that soft segments of PU530 are amorphous and hard segments of this polymer are crystalline. Hydrophilicities of the synthesized polymers were studied and the results showed that PU2000 is more hydrophilic in nature than PU530. Curcumin was loaded in the polyurethanes by electrospinning process in different contents. The release rate of curcumin from polyurethane matrices as well as anti-bacterial activity of the mats was investigated and the results demonstrated that PU2000, because of good mechanical and anti-bacterial properties, is a good candidate for wound dressing applications.

\section{Compliance with ethical standards}

Conflict of interest A. Shababdoust declares that he has no conflict of interest. M. Ehsani declares that he has no conflict of interest. P. Shokrollahi declares that she has no conflict of interest. M. Zandi declares that she has no conflict of interest.

Research involving human and/or animal This article does not contain any studies with human participants or animals performed by any of the authors.

Open Access This article is distributed under the terms of the Creative Commons Attribution 4.0 International License (http://creativecommons.org/licenses/by/4.0/), which permits unrestricted use, distribution, and reproduction in any medium, provided you give appropriate credit to the original author(s) and the source, provide a link to the Creative Commons license, and indicate if changes were made.

\section{References}

Abdollahi MF, Zandi M, Shokrollahi P, Ehsani M (2015) Synthesis and characterization of curcumin segmented polyurethane with induced antiplatelet activity. J Polym Res 22:1-10

Alexis F, Venkatraman SS, Rath SK, Boey F (2004) In vitro study of release mechanisms of paclitaxel and rapamycin from drug-incorporated biodegradable stent matrices. J Controll Release 98:67-74

Allport DC, Mohajer AA (1973) Property-structure relationships in polyurethane block copolymers. In: Allport DC, James WH (eds) Block copolymers. Applied Science Publishers, New York, pp 443-492

Aulton ME (2002) Pharmaceutics: the science of dosage form design. Churchill Livingstone, London

Bajsic EG, Rek V, Sendijarevic A, Sendijarevic V, Frisch K (2000) DSC study of morphological changes in segmented polyurethane elastomers. J Elastom Plast 32:162-182

Bonart R (1968) X-ray investigations concerning the physical structure of cross-linking in segmented urethane elastomers. J Macromol Sci Part B 2:115-138

Brahatheeswaran D et al (2012) Hybrid fluorescent curcumin loaded zein electrospun nanofibrous scaffold for biomedical applications. Biomed Mater 7:045001

Chandra D, Gupta S (1972) Anti-inflammatory and anti-arthritic activity of volatile oil of Curcuma longa (Haldi). Indian J Med Res 60:138

Chen Y, Lin J, Fei Y, Wang H, Gao W (2010) Preparation and characterization of electrospinning PLA/curcumin composite membranes. Fibers Polym 11:1128-1131

Clough S, Schneider N (1968) Structural studies on urethane elastomers. J Macromol Sci Part B 2:553-566

Clough S, Schneider N, King A (1968) Small-angle X-ray scattering from polyurethane elastomers. J Macromol Sci Part B 2:641-648

Demir MM, Yilgor I, Yilgor E, Erman B (2002) Electrospinning of polyurethane fibers. Polymer 43:3303-3309

Erenoğlu C, Kanter M, Aksu B, Sağıroğlu T, Ayvaz S, Aktaş C, Erboğa M (2011) Protective effect of curcumin on liver damage induced by biliary obstruction in rats. Balk Med J 28:352-357 
Fu SZ et al (2014) Acceleration of dermal wound healing by using electrospun curcumin-loaded poly ( $\varepsilon$-caprolactone) poly (ethylene glycol) poly ( $\varepsilon$-caprolactone) fibrous mats. J Biomed Mater Res Part B 102:533-542

Goel A, Kunnumakkara AB, Aggarwal BB (2008) Curcumin as "Curecumin": from kitchen to clinic. Biochem Pharmacol 75:787-809

Gogolewski S (1989) Selected topics in biomedical polyurethanes. Rev Colloid Polym Sci 267:757-785

Gopal R, Kaur S, Ma Z, Chan C, Ramakrishna S, Matsuura T (2006) Electrospun nanofibrous filtration membrane. J Membr Sci 281:581-586

Gunes H, Gulen D, Mutlu R, Gumus A, Tas T, Topkaya AE (2013) Antibacterial effects of curcumin: an in vitro minimum inhibitory concentration study. Toxicol Ind Health 32(2):246-250

Himesh S, Sharan PS, Mishra K, Govind N, Singhai A (2011) Qualitative and quantitative profile of curcumin from ethanolic extract of Curcuma longa. Int Res J Pharm 2:180-184

Huei-Chen H, Tong-Rong J, Sheau-Farn Y (1992) Inhibitory effect of curcumin, an anti-inflammatory agent, on vascular smooth muscle cell proliferation. Eur J Pharmacol 221:381-384

Jain P, Pradeep T (2005) Potential of silver nanoparticle-coated polyurethane foam as an antibacterial water filter. Biotechnol Bioeng 90:59-63

Khil MS, Cha DI, Kim HY, Kim IS, Bhattarai N (2003) Electrospun nanofibrous polyurethane membrane as wound dressing. J Biomed Mater Res Part B 67:675-679

Krol P (2007) Synthesis methods, chemical structures and phase structures of linear polyurethanes. Properties and applications of linear polyurethanes in polyurethane elastomers, copolymers and ionomers. Prog Mater Sci 52:915-1015

Kulac M et al (2013) The effects of topical treatment with curcumin on burn wound healing in rats. J Mol Histol 44:83-90

Li WJ, Laurencin CT, Caterson EJ, Tuan RS, Ko FK (2002) Electrospun nanofibrous structure: a novel scaffold for tissue engineering. J Biomed Mater Res 60:613-621

Li G, Li D, Niu Y, He T, Chen KC, Xu K (2014) Alternating block polyurethanes based on PCL and PEG as potential nerve regeneration materials. J Biomed Mater Res Part A 102:685-697

Loh XJ, Sng KBC, Li J (2008) Synthesis and water-swelling of thermo-responsive poly (ester urethane) s containing poly ( $\varepsilon$-caprolactone), poly (ethylene glycol) and poly (propylene glycol). Biomaterials 29:3185-3194

Malucelli G, Priola A, Ferrero F, Quaglia A, Frigione M, Carfagna C (2005) Polyurethane resin-based adhesives: curing reaction and properties of cured systems. Int J Adhes Adhes 25:87-91

Martins C et al (2009) Curcumin as a promising antifungal of clinical interest. J Antimicrob Chemother 63:337-339

Merrell JG, McLaughlin SW, Tie L, Laurencin CT, Chen AF, Nair LS (2009) Curcumin-loaded poly ( $\varepsilon$-caprolactone) nanofibres: diabetic wound dressing with anti-oxidant and anti-inflammatory properties. Clin Exp Pharmacol Physiol 36:1149-1156

Nagarajan S, Reddy BSR, Tsibouklis J (2011) In vitro effect on cancer cells: synthesis and preparation of polyurethane membranes for controlled delivery of curcumin. J Biomed Mat Res Part A 99:410-417

Natu MV, de Sousa HC, Gil MH (2011) Electrospun drug-eluting fibers for biomedical applications. Active implants and scaffolds for tissue regeneration. Stud Mechanobiol Tissue Eng Biomater 8:57-85

Nguyen TTT, Chung OH, Park JS (2011) Coaxial electrospun poly (lactic acid)/chitosan (core/shell) composite nanofibers and their antibacterial activity. Carbohydr Polym 86:1799-1806

Patel AC, Li S, Wang C, Zhang W, Wei Y (2007) Electrospinning of porous silica nanofibers containing silver nanoparticles for catalytic applications. Chem Mater 19:1231-1238

Pathak S, Sharma A, Khanna A (2009) Value addition to waterborne polyurethane resin by silicone modification for developing high performance coating on aluminum alloy. Prog Org Coat 65:206-216

Pennings A, Knol K, Hoppen H, Leenslag J, Van der Lei B (1990) A two-ply artificial blood vessel of polyurethane and poly (L-lactide). Colloid Polym Sci 268:2-11

Pradhan KC, Nayak P (2012) Synthesis and characterization of polyurethane nanocomposite from castor oil-hexamethylene diisocyanate (HMDI). Adv Appl Sci Res 3:3045

Ranjbar-Mohammadi M, Bahrami SH (2016) Electrospun curcumin loaded poly ( $\varepsilon$-caprolactone)/gum tragacanth nanofibers for biomedical application. Int J Bio Macro 84:448-456

Saeed SM, Mirzadeh H, Zandi M, Barzin J (2017) Designing and fabrication of curcumin loaded PCL/PVA multi-layer nanofibrous electrospun structures as active wound dressing. Prog Biomater 6(1-2):39-48. https://doi.org/10.1007/s40204-017-0062-1

Sampath M, Lakra R, Korrapati P, Sengottuvelan B (2014) Curcumin loaded poly (lactic-co-glycolic) acid nanofiber for the treatment of carcinoma. Colloid Surf B 117:128-134

Scholes S, Unsworth A, Jones E (2007) Polyurethane unicondylar knee prostheses: simulator wear tests and lubrication studies. Phys Med Bio 52:197

Sivak WN, Pollack IF, Petoud S, Zamboni WC, Zhang J, Beckman EJ (2008) LDI-glycerol polyurethane implants exhibit controlled release of DB-67 and anti-tumor activity in vitro against malignant gliomas. Acta Biomater 4:852-862

Skarja G, Woodhouse K (1998) Synthesis and characterization of degradable polyurethane elastomers containing an amino acidbased chain extender. J Biomater Sci Polym Ed 9:271-295

Souguir H, Salaün F, Douillet P, Vroman I, Chatterjee S (2013) Nanoencapsulation of curcumin in polyurethane and polyurea shells by an emulsion diffusion method. Chem Eng J 221:133-145

Sun X-Z, Williams GR, Hou X-X, Zhu L-M (2013) Electrospun curcumin-loaded fibers with potential biomedical applications. Carbohydr Polym 94:147-153

Suwantong O, Opanasopit P, Ruktanonchai U, Supaphol P (2007) Electrospun cellulose acetate fiber mats containing curcumin and release characteristic of the herbal substance. Polymer 48:7546-7557

Unnithan AR, Gnanasekaran G, Sathishkumar Y, Lee YS, Kim CS (2014) Electrospun antibacterial polyurethane-cellulose acetate-zein composite mats for wound dressing. Carbohydr Polym 102:884-892

Varghese S, Gatos K, Apostolov A, Karger Kocsis J (2004) Morphology and mechanical properties of layered silicate reinforced natural and polyurethane rubber blends produced by latex compounding. J Appl Polym Sci 92:543-551

Yang Q-f, Qu J-q, Chen H-q (2004) Technical development of waterborne polyurethane paint. Chem Technol Mark 10:003

Yu LS et al (1989) New polyurethane valves in new soft artificial hearts. ASAIO J 35:301-303

Zeng J, Xu X, Chen X, Liang Q, Bian X, Yang L, Jing X (2003) Biodegradable electrospun fibers for drug delivery. J Controll Rel 92:227-231

Zhang Y, Ouyang H, Lim CT, Ramakrishna S, Huang ZM (2005) Electrospinning of gelatin fibers and gelatin/PCL composite fibrous scaffolds. J Biomed Mater Res Part B 72:156-165

Zhu W et al (2015) Y-shaped biotin-conjugated poly (ethylene glycol)poly (epsilon-caprolactone) copolymer for the targeted delivery of curcumin. J Colloid Inter Sci 443:1-7

Publisher's Note Springer Nature remains neutral with regard to jurisdictional claims in published maps and institutional affiliations. 


\section{Affiliations}

\section{A. Shababdoust ${ }^{1} \cdot$ M. Ehsani ${ }^{1} \cdot$ P. Shokrollahi ${ }^{2} \cdot M$. Zandi $^{2}$}

$\triangle$ M. Ehsani

m.ehsani@ippi.ac.ir

M. Zandi

m.zandi@ippi.ac.ir

1 Plastics Department, Iran Polymer and Petrochemical Institute, Tehran, P.O. Box 14965/115, Iran

2 Biomaterials Department, Iran Polymer and Petrochemical Institute, Tehran, P.O. Box 14965/115, Iran 